\title{
Traditional or contemporary? The prevalence of performance measurement system types
}

\begin{abstract}
Purpose: The paper seeks to examine the prevalence of traditional versus contemporary (balanced) types of performance measurement system (PMS) in an emerging economy and link incidence to key organisational factors of size, age and ownership. Design/methodology/approach: Data on design and use of PMSs are collected through a questionnaire survey $(n=149)$ of electrical and electronic firms. Hierarchical cluster analysis identifies two PMS groups and assigns them to traditional and contemporary types, and then links them to key organisational factors via contingency tables. Findings: Use of contemporary PMS dominates the sample. PMS type is significantly associated with size and ownership, while age is not. Firms more likely to use contemporary PMSs are foreign-owned and large in terms of number of employees. Research limitations/implications: This surveybased research employs multivariate analysis and therefore standard limits for such statistical work apply. Results rely on hierarchical cluster analysis. Practical implications: If balanced approaches are more effective, as is argued by many, then a firm without such a style of PMS is at a competitive disadvantage given the high incidence of use. Originality/value: The paper establishes a framework for a contemporary type of PMS that integrates balanced scorecard and other balanced approaches, then collects data in an emerging economy. Links use of contemporary PMS type to key organisational factors.
\end{abstract}

Keyword: Balanced scorecard; Performance management systems; Performance measures 